\title{
OVERVIEW OF THE HINKLEY POINT C EPR PROJECT 'J0' AND BEYOND
}

\author{
James Dyrda ${ }^{1}$ \& Richard Morrison ${ }^{1}$ \\ ${ }^{1}$ EDF NNB Gen Co, \\ Bridgewater House, Counterslip, Bristol BS1 6BX, UK \\ james.dyrda@nnb-edfenergy.com
}

\begin{abstract}
The twin unit EPR construction at Hinkley Point $\mathrm{C}$ is the first nuclear new build project to be undertaken in the UK in a generation. Moreover, it is now the country's only new reactor project still in progress. The station's two 1650 MWe plants [1] will complement the UK's decarbonised energy mix with addition of approximately $7 \%$ of the current national requirement. In 2019 , less than three years from the final investment decision, the 'J0' milestone was reached. This represents the end of the preparatory works, including all the common raft nuclear island concrete for Unit 1, enabling the upwards erection of the reactor containment and other support buildings. In addition to this, important milestones such as launch of the first tunnel boring machine, to tunnel the Unit 1 sea-water intake pipe have all been achieved. Over the coming years, the project will need to evolve in order to meet the increasing complexity and multi-organisation scope, which will present a challenging delivery environment. In order to support this, a UK-based Design Authority works on review, verification and acceptance of the HPC design including its UK specificities. This allows NNB, as licensee, to own its design and prepare the pre-commissioning safety case and operational strategies, defensible to the relevant UK regulators. As an example, this paper presents the roles and responsibilities in the Reactor Technology Team. This small, flexible team is involved in technical oversight of all aspects of the fuel \& core design, through normal operations, anticipated and design-basis faults, severe accidents and radiological consequence estimation.
\end{abstract}

KEYWORDS: EPR, PWR, new-build

\section{INTRODUCTION}

Since its regulatory go-ahead and final investment decision (FID), significant progress on ground works and civil engineering has been made on the Hinkley Point C (HPC) EPR reactor project. The site is located on the coast of the Bristol channel in the South-West county of Somerset. It neighbours the operational AGR B-reactor and the decommissioned Magnox A-site. This paper, though non-technical in nature, aims first at providing a generic update to the reactor physics technical community. Its publication comes a short time after the successful completion of the first significant milestones, and allows some contextual review of the modern nuclear new-build construction techniques employed to make the project practically and economically viable. Furthermore, it presents future project milestones on the path to plant commissioning and full operation. 
Further to the construction challenges are those to the licensee in terms of organisation, expertise and experience of qualified personnel. This challenge is enlarged somewhat by the multi-organisation and multinational conditions for modern new build reactors. Ensuring nuclear safety of the highest degree against the backdrop of reactor design import and joint public-private funding is the top priority. It is acknowledged that public acceptance and confidence are underwritten by this safety demonstration and provides an additional feedback to the economic security of nuclear power renewal and de-carbonisation of energy. This paper also presents a snapshot of a key team within NNB who act as Intelligent Customer (IC) for the reactor core design, function and safety. Some of the team's training and organisational strategies of a relatively innovative nature are also reviewed, such that they might be of general interest to groups of technical staff under similar circumstances.

\section{ACHIEVEMENT OF MAJOR MILESTONES - UNIT 1}

\subsection{Nuclear Island 'J0' Final Concrete Pour}

In June 2019, less than three years from the FID date and in line with the baseline projection, the 'J0' milestone was reached. This represents the final concrete pour on the Nuclear Island 'Common Raft', the $4 \mathrm{~m}$ thick foundation platform for HPC reactor Unit 1. This brought to a close the majority of below ground activities and enables the upwards erection of the reactor containment and others support buildings. The last of these concrete pours took a total of three continuous days, totalling a volume of approximately $9000 \mathrm{~m}^{3}$ of material - a new record for the largest continuous concrete pour for construction of any type in the UK. This was the last of five Unit 1 Common Raft segments - the first of which was poured in December 2018.

Moving into the post- 'J0' phase of the project is recognised as both an achievement and a challenge. It allows many new organisations, contractors and equipment onto site and multiple, inter-connected delivery activities to commence. Over the coming years, the project will need to evolve in order to meet the increasing complexity and multi-organisation scope, which will present a challenging delivery environment. Works must be advanced at the required pace, whilst ensuring an uncompromised focus on nuclear safety and quality assurance.

\subsection{Launch of First Tunnel Boring Machine}

August 2019 saw the placement and attachment of the cutter head to the tunnel boring machine 'Mary'; the 1200 tonnes machine, $7.7 \mathrm{~m}$ in diameter, which will tunnel several kilometres beneath the sea-bed to form the sea-water heat sink inlet for Unit 1. It does this by breaking up the rock in front of it as the machine is pushed forwards, with the broken earth and rock then moving through the machine on a screw conveyor. Preparatory work for this consisted of construction of a launch adit (a smooth concrete face inset several metres into the rock). The front shield section was then fully inserted and a supporting launch frame attached. As each length of tunnel is dug, permanent reinforcement rings are installed. The same method will be used eventually for the Unit 2 intake tunnel and the shared Unit $1 \& 2$ outfall to dig a total of more than $8 \mathrm{~km}$ of piping.

\subsection{Conventional Island Heat Sink \& CRF Piping}

Other important civil engineering works have represented the bulk of completed activity on site thus far. This has encompassed the large Unit 1 heat sink fore bay and construction of its pump house reinforced slab and outer walls. Similar work for Unit 2 has also been started. Significant progress has also been made on installation of the steam re-condensation 'CRF' system piping that brings sea-water from the heat sink, 
via the pump house to the Conventional Island (turbine generator) area of site. Complex pipe sections were transported to site as hundreds of pre-cast concrete pieces to be assembled with in-situ concrete and steel rebar reinforcement to then be added. This reinforcement has presented an engineering challenge in terms of its complexity and density.

\section{UPCOMING MILESTONES - UNITS $1 \& 2$}

\subsection{Technical Galleries \& MEH}

Steady progress has been made on the Technical Galleries - large round-site trenches which route the subterranean mechanical, electrical and HVAC (MEH) services; more than $1700 \mathrm{~m}$ have been prepared, out of an overall site total of about $7200 \mathrm{~m}$. This is due to be followed by MEH bulk installation within the Nuclear Island, Conventional Island and Galleries, and subsequently by the first standard instrumentation and control (I\&C) equipment. In addition, the polar crane that provides the large lifting capability internal to the reactor containment building, will be delivered and positioned.

\subsection{Unit 2 Nuclear Island}

The construction schedule of Unit 2 currently tracks at the intended one-year lag behind Unit 1 . This means that the pre-stressing gallery and pre-cast concrete roof slabs previously completed for Unit 1 are in progress, the first Common Raft concrete poured and the ' $\mathrm{J} 0$ ' milestone for Unit 2 should be achieved in 2020. The twin unit construction strategy with a one-year time lag is intended to make the best use of a skilled workforce to repeat successful work, learn from experience and deliver savings in schedule and cost. It should be noted that the Chinese EPR project at Taishan was the only other to build two units in parallel. General operating experience has been gained from both other EPR builds in France and Finland, but Taishan in particular offers learning opportunities from a similar site and schedule. Furthermore, this information may now cover successful commissioning and early operation, since both units have now reached full power and are in their first fuel cycles.

\subsection{Containment Fabrication \& Unit 1 Dome Lift}

Following ' $\mathrm{O} 0$ ' the remainder of the site pre-construction and fabrication facilities to support the construction of the Reactor Building are being completed. These fabrication facilities are a key lesson learnt from other EPRs to provide a controlled, weather-proof environment for efficient fabrication of the containment liner cup, gusset, rings and dome for the Reactor Building. This environment means that weather does not affect either the workforce, activities or the materials and quality of the final product. Fabrication within this weather-proof 'bunker 5' of the steel liner cup and gusset was the first to be started, ready for successful lifting into place.

Also in readiness for the reactor building construction and dome lift, the next major target milestones, the world's largest model of crane (Sarens SGC-250) has been brought onto site. This crane, dubbed 'Big Carl', has a maximum load moment of 250,000 metric tonnes, allowing it to lift 5000 tonnes or, even at a radius of 100 metres, up to 2000 tonnes. Construction and pre-stressing of the inner and outer wall structures of the Unit 1 reactor building will be completed, culminating in the final dome lift. As a means of reference to the overall scale of the project, the following indicative totals can be considered:

By the point of containment dome lift, project will have:

- Installed 150,909 (75\% of the total required) tonnes of rebar.

- Poured $715,291 \mathrm{~m}^{3}$ (72\% of the total required) of structural concrete. 
This is the equivalent of approximately 4200 tonnes of rebar and $21,000 \mathrm{~m}^{3}$ of concrete per month, whereas the Unit 1 Reactor Building itself will have consumed 10,440 tonnes of rebar and 45,364 $\mathrm{m}^{3}$ of concrete.

On the back of the dome lift, subsequent milestones will be set to complete the remaining project schedule. This will culminate in commissioning works for operation, followed by fuel receipt to site and first criticality and power operation. A computer-generated representative view of the completed HPC site is shown in Figure 1.

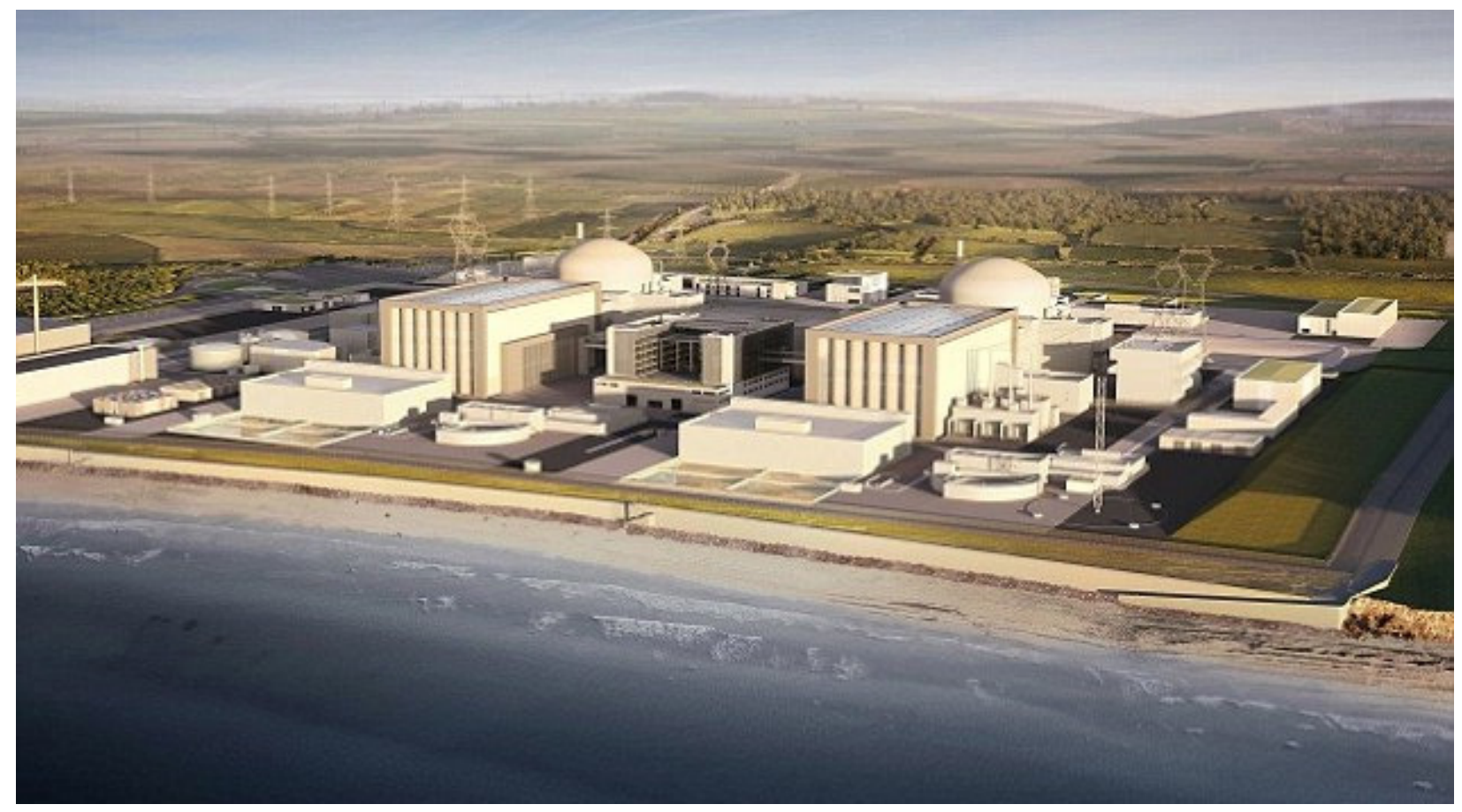

Figure 1. Computer-generated View of the Completed HPC Station.

\section{DESIGN AUTHORITY - REACTOR TECHNOLOGY TEAM}

The NNB organisation holds within it the role identified as the Design Authority (DA), whilst Edvance and CNEPE, French institutes within EDF group hold the role of Responsible Designer (RD). Within the DA, the reactor technology team comprises mostly single discipline specialists, each responsible for oversight, review, understanding and receipt of technical work and safety case preparation in their respective areas. Delivery of each piece of work is first agreed under a specification, setting out the calculations and selected codes. The resulting technical reports are then verified and accepted, with surveillance scrutiny proportionate to the nuclear safety significance/relative risk. As a collective, these functions satisfy the nuclear baseline roles for the reactor design in compliance with UK Nuclear Licence Condition 12 [2]. In addition, the team applies UK specific requirements and interpretation - the most salient example of which is application of the ALARP (As Low as Reasonably Practicable) principle [3]. NNB ensures it is able to demonstrate risk reduction to ALARP has been applied both individually and collectively to faults and identified hazards, regardless of meeting the regulation basic safety level / objective targets [4]. 


\subsection{Descriptions of Discipline Areas}

The main disciplines and roles within the team are briefly described below. These are shown diagrammatically in Figure 2, along with the associated support personnel and collaborating groups.

- $\quad$ Fault Studies

Responsible for the Design Basis Fault Studies elements of the HPC safety case and compliance with NNB requirements and safety principles. Includes oversight of safety doctrine, acceptance criteria, process of fault identification, Fault Studies transient analyses and development of safety case structure.

- Thermal Hydraulics

Core Thermal Hydraulics is a transverse discipline that supports a number of other topics in the reactor technology area. It is involved in the DNB safety case, fault studies transients, structural integrity of the primary components and dry fuel storage analysis. These involve a range of tools such as sub-channel codes, system codes or CFD.

- Fuel \& Core Components Engineering

This role deals with the engineering design and performance of fuels, cladding, assembly materials and other core components such as control rods, thimble plug assemblies and neutron sources. Performance during cycle, fuel pond storage and long term dry storage are considered. Phenomenological and empirical modelling tools are employed to analyse this range of conditions.

- Criticality Safety and Reactor Physics

Responsible for ensuring defense against unintended criticality of nuclear fuel during receipt, storage and handling. Provides support to operational and transient analysis through the fuel management schemes, reactivity control functions, depletion studies, radiation instrumentation, decay heat and shielding calculations.

- $\quad$ Severe Accidents

Severe accident analyses demonstrate that high energy phenomena with a potential for jeopardizing the containment are precluded by design and that progression of a Severe Accident does not lead to large and early releases. The calculations involve molten corium progression (in- and ex-vessel), Molten-Core Concrete Interaction (MCCI), CFD hydrogen distribution and combustion and, containment pressure and temperature loads.

- Radiological Consequences

Radiological Consequences covers assessment of the detriment to workers and members of the public of any potential release of radioactive material from the site. The calculations involve atmospheric dispersion modelling, dose evaluations, and risk estimates based on probabilistic meteorological models for the Level 3 Probabilistic Safety Analysis (PSA).

- Normal Operations

HPC has extensive engineered safety features to stop the main safety protection systems from being challenged, known as the preventative line. Normal operations cover plant performance analysis, for example in response to national grid load change requirements, and preventative line analysis. Interactions with plant operations and procedures are a key interface.

- Macro-Activity / Relationship Lead

This role ensures that NNB/RTT (the IC) works efficiently with EDVANCE (the RD), defining the review strategy and that open points / technical issues are dealt with efficiently and progress as necessary. They also oversee the coordination of cross-cutting topics, providing broad technical support where multi-discipline knowledge is required. 


\subsection{Strategic Considerations and Innovations}

The UK nuclear industry can be viewed as in a somewhat transitionary phase. There has been active interest and investment in new build power plants, with several designs in the Generic Design Approval (GDA) route with the ONR, the national regulator. However, of the three designs to pass GDA step 4, only EPR remains in progress. The construction of HPC is the first new build in a generation, since the commissioning of the Sizewell B (SZB) station in 1995; the only other PWR on the UK grid. Hence, there has been somewhat of a gap in practical experience and skills related to PWR technology that presents a strategic challenge to the organisation. In parallel, the existing UK fleet of AGR plants is heading towards the end of its operational life, with end of operation and decommissioning plans now being determined. In order to address this challenge and maintain a consistency of skills and personnel, several management strategies have been applied by the team and NNB DA more generally; the main examples of which are:

$>$ Graduate pipelining - active succession planning is put into place by identifying roles for STEM graduates recruited into the company. Following building of general experience across various placements, specialist practitioner multi-year secondments, both in UK \& France EDF locations is offered. This ensures Intelligent Customer functions are eventually undertaken by SQEP personnel in the near-term future, despite the limited permanent posts available in the present industry setting.

$>$ Contractor support - flexible, contracted support staff are available to each technical area, normally from individuals with wide and long-standing industry experience. They may also provide independent review services or advice/mentoring. This support ensures NNB can meet emergent demands and are not reliant on individual knowledge or availability. Involvement of these persons also aids the transfer of skills and knowledge to EDF as the licence-holder, which might otherwise not be retained.

$>$ EDF Nuclear Generation Limited (UK) structured collaboration - partnerships with persons working on the present UK fleet have been used in technical analysis and review work, and in contract negotiations. This is especially in areas where established UK approaches require consideration. It leverages national best practice and experience, especially from SZB. It also fits with the 'one-operator' future direction planned for HPC and encourages retention of corporate knowledge, especially considering the planned closure of AGR plants over the coming decades.

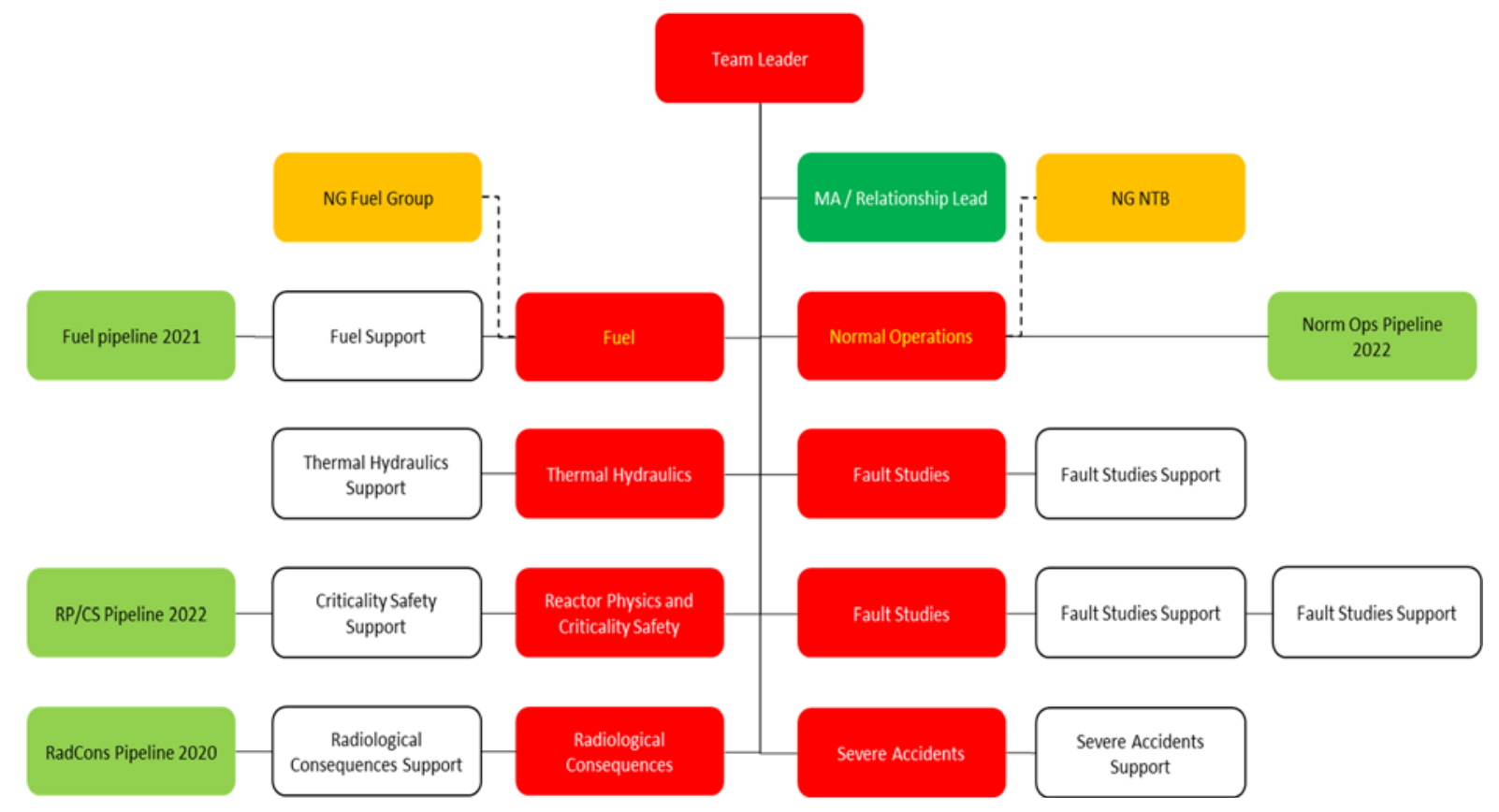

Figure 2. Reactor Technology Team Organisational Diagram. 


\section{CONCLUSIONS}

In order to respond in time to the threat of climate change, the UK has set an aggressive "net-zero" ambition to completely de-carbonise energy by 2050 and extensively electrify transport and industry. Mixing large amounts of renewables with reliable, proven, low carbon nuclear is recognised as a good mix to give the UK a secure and affordable electricity supply. Examples in other countries show this combination has allowed effective decarbonisation. The demonstration of completing important early milestones such as those described in this paper, lends credibility to nuclear new-build and the possibility to replicate and repeat in a scalable fashion. In this way, it is hoped that HPC dome lift will be a catalyst to bring about a financial commitment for two further EPR units at Sizewell C (SZC) in Suffolk.

Economically, for more new nuclear to be built, government and industry agree that costs must be lowered. Clearly, new nuclear costs are driven by construction and financing, both of which can be cheaper through design replication. A significant proportion of costs can also be linked to approving a design and its componentry to meet the exacting regulatory standards. For an identical second of a kind project, most of these costs are avoided if the design is unchanged. Quantities of materials such as concrete and steel can be known with more precision. Processes and planning can also be improved and streamlined. The two new proposed units at SZC, would in the most part be identical in design to HPC so as to maximise such savings to the greatest extent [5].

Reproducing the design as closely as possible and engaging the same people can also assist scaled, cheaper construction. The resulting lower risk will allow a cheaper, competitive financial model. This approach widens the possible sources of financing through multiple private investment. Finally, HPC has demonstrated the huge impact of nuclear projects on delivering training, skills and employment, which will both support SZC as well as being expanded as a result. The organisation and its personnel will have been proven throughout the delivery and construction of HPC and the arrangements presented in this paper exemplify how technical teams can be prepared to efficiently replicate activities for SZC.

\section{ACKNOWLEDGMENTS}

The writing of this paper was made possible thanks to information provided by the HPC communications team. Thanks are also due to colleagues in the Reactor Technology Team for their valuable support and contributions.

\section{REFERENCES}

1. EPR Pre-Construction Safety Report (PCSR), UKEPR-0002-011 Issue 04, Areva NP \& EDF, 2012 (http://www.epr-reactor.co.uk/).

2. Licence Condition Handbook, Office for Nuclear Regulation, February 2017 (http://www.onr.org.uk/documents/licence-condition-handbook.pdf).

3. Safety Assessment Principles for Nuclear Facilities, Office for Nuclear Regulation, 2014 Edition, Revision 0 (http://www.onr.org.uk/saps/saps2014.pdf).

4. NS-TAST-GD-005 Revision 9, Guidance on the Demonstration of ALARP, Office for Nuclear Regulation, March 2018 (http://www.onr.org.uk/operational/tech_asst_guides/ns-tast-gd-005.pdf).

5. "Needed but not at any price - how to lower the cost of nuclear", H Cadoux-Hudson, SZC News, 28 Jan 2019 (https://www.edfenergy.com/energy/nuclear-new-build-projects/sizewell-c/newsviews/needed-but-not-at-any-price-how-to-lower-the-cost-of-nuclear). 